\title{
Efficiency Factors for Plastic Design in Concrete: Influence of Brittleness in Compression
}

\author{
Francesco Moccia $^{1}$, Miguel Fernández Ruiz ${ }^{2}$ and Aurelio Muttoni ${ }^{3}$
}

${ }^{1} \mathrm{PhD}$ candidate, Ecole Polytechnique Fédérale de Lausanne, ENAC, CH-1015

Lausanne, Switzerland, francesco.moccia@epfl.ch, +41216932870

${ }^{2} \mathrm{PhD}$, Ecole Polytechnique Fédérale de Lausanne, ENAC, CH-1015 Lausanne, Switzerland, miguel.fernandezruiz@epfl.ch, +41216932889

${ }^{3}$ Professor, PhD, Ecole Polytechnique Fédérale de Lausanne, ENAC, CH-1015

Lausanne, Switzerland, aurelio.muttoni@epfl.ch,+41216932881

\begin{abstract}
A large number of design approaches for structural concrete rely on the applicability of limit analysis. This is for instance the case of bending and shear design in members with transverse reinforcement, where it is assumed that plastic compression fields develop in the concrete. The behaviour of concrete in compression, however, cannot be directly assumed as perfectly plastic. In order to consistently apply limit analysis, the compressive strength of concrete is usually reduced by a number of strength reduction factors. In this paper, the factor accounting for the brittle behaviour of concrete in compression is reviewed. The aim is to assess the need for a brittleness factor when determining the capacity of concrete columns subjected to pure compression. Theoretically, the need for this factor is justified as a reinforced column is a composite system, where an interaction (redistribution of forces) potentially occurs amongst the longitudinal bars and the concrete as well as with the transverse (confinement) reinforcement.

A total of 207 specimens from the scientific literature were considered in this research. They were all characterized by low slenderness (no second order effects) and presented variable concrete compressive strength (24 to $200 \mathrm{MPa}$ ), cross-section (square or circular), longitudinal reinforcement ratio (0.8 to $6.8 \%)$, transverse reinforcement ratio $(0.1$ to $3.5 \%)$, tie arrangement and spacing, yield strength of the longitudinal reinforcement (260 to $820 \mathrm{MPa}$ ) and yield strength of the transverse reinforcement (300 to $1000 \mathrm{MPa}$ ). Their compressive capacity was evaluated according to a rigid-plastic approach as well as to EN1992-1-1:2004. On that basis, a series of conclusions are drawn on the need for a brittleness factor.
\end{abstract}

Key-words: limit analysis, brittleness factor, comparison to tests, reinforced concrete

\section{INTRODUCTION}

A large number of design approaches for structural concrete members are based on limit analysis in which it is assumed that at failure materials eventually exhibit a plastic behaviour. This is the case of EN1992-1-1:2004 for instance with reference to shear with transverse reinforcement and bending. The assumption of a plastic behaviour is in good agreement for reinforcing steel since it is a ductile material with considerable deformation capacity (Figure 1). A rigid-plastic stress-strain relation is, on the other hand, less suitable for the behaviour of concrete in compression (Figure 
2) due to the softening response after reaching its maximum strength. This brittle behaviour is in fact dependent on the concrete resistance, and is characterized by a more brittle response for higher concrete strengths. Therefore, in order to consistently apply limit analysis, a plastic resistance $f_{c p}$ is usually adopted.

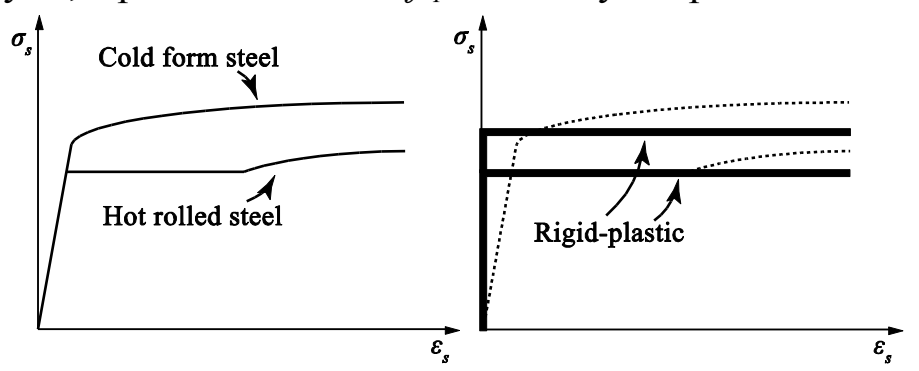

Figure 1. Actual stress-strain relation of reinforcing steel (left), assumed rigidplastic behavior (right)

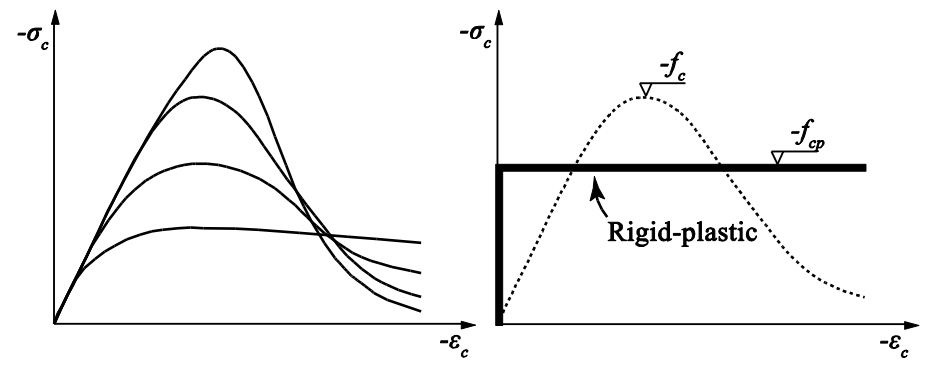

Figure 2. Stress-strain relationship of uniaxially compressed concrete with different capacities (left), assumed rigid-plastic behavior (right)

The plastic resistance $f_{c p}$ is normally defined as follows:

$$
f_{c p}=\eta_{f c} \cdot f_{c}
$$

where $f_{c}$ is the value of the concrete compressive strength measured on a cylinder and $\eta_{f c}$ is a strength reduction factor that accounts for the concrete brittleness. Background for the need of a brittleness factor can be found in Exner (1979). Muttoni (1990), on the basis of results for girders with shear reinforcement characterized by the concrete crushing, proposed a general formulation for this factor as follows:

$$
\eta_{f c}=\left(\frac{f_{c 0}}{f_{c}}\right)^{1 / 3} \leq 1.0
$$

where $f_{c 0}=30 \mathrm{MPa}$ for normal weight concrete and $f_{c 0}=20 \mathrm{MPa}$ for lightweight concrete. The latter formulation was adopted by the fib Model Code 2010 in the following format:

$$
\eta_{f c}=\left(\frac{30}{f_{c k}}\right)^{1 / 3} \leq 1.0 \text {, where } f_{c k} \text { is in MPa. }
$$

In what follows, the need of a concrete brittleness factor is investigated on the basis of a database of 207 columns. The compressive capacity of the specimens is evaluated according to different procedures and the results are compared to the measured strengths. It should be noted that all the calculations were performed using mean values of the steel and concrete strengths (noted as $f_{c}$ and $f_{y}$ hereafter) measured during the experimental campaigns. 


\section{EN 1992-1-1:2004}

The general procedure of the EN 1992-1-1:2004 to compute the strength of concrete columns consists of adding the contributions of steel and concrete in compression (according to a constant strain profile in compression as in Figure 6.1 of the EN 1992-1-1:2004). The load carrying capacity is therefore calculated as:

$$
N_{R}=\sigma_{s} \cdot A_{s}+f_{c} \cdot A_{c}
$$

where

- $\sigma_{s}$ is the reinforcing steel stress

- $A_{s}$ is the cross-sectional area of the longitudinal reinforcement

- $\quad f_{c}$ is the mean value of the cylinder compressive strength of concrete

- $A_{c}$ is the cross-sectional area of the concrete and is obtained by subtracting the longitudinal reinforcement area from the gross area of the cross-section

It can be noted that, in this expression, no brittleness factor is accounted for.

Equation (4) is adopted to assess the load carrying capacity of the 207 investigated specimens. For each specimen the ratio between the measured failure load and the axial load obtained with the general procedure of the EN1992-1-1:2004 is computed. This ratio is represented as a function of the compressive strength of concrete $f_{c}$ in Figure 3.

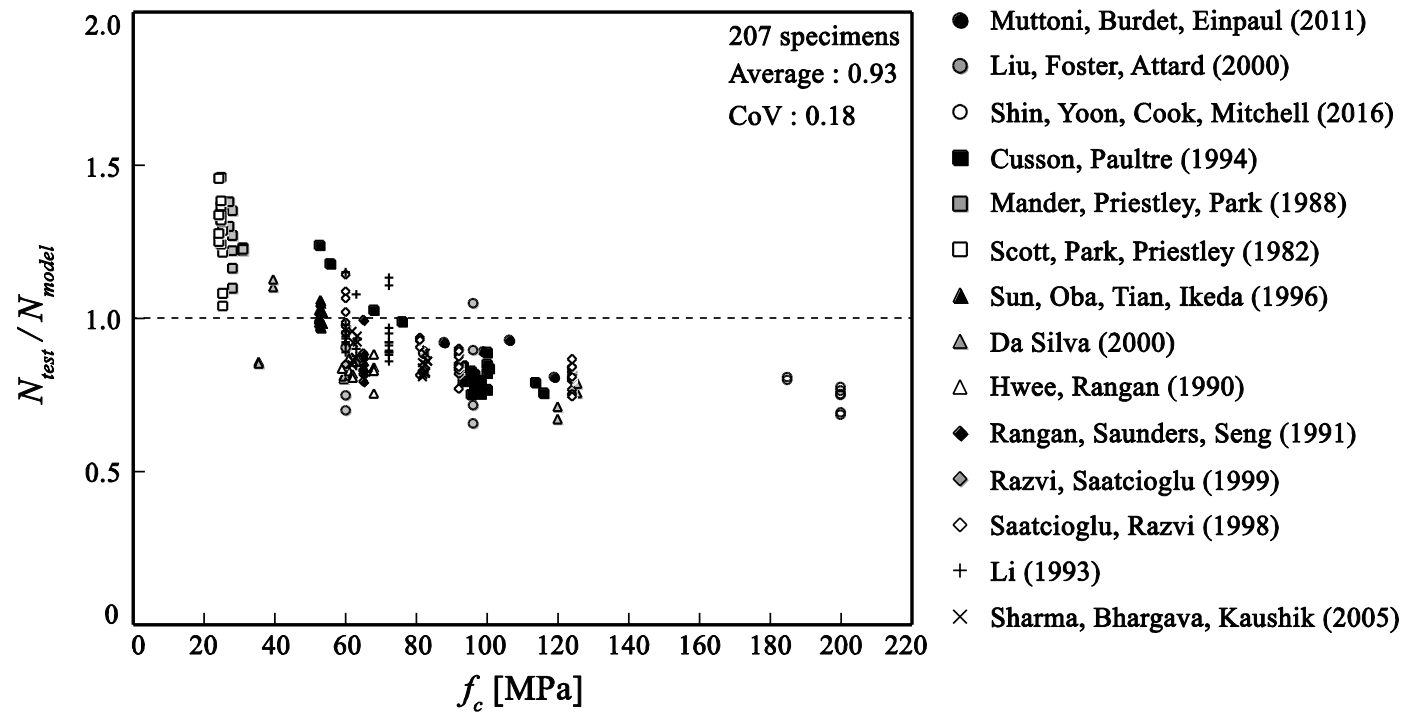

Figure 3. Comparison between column tests and EN1992-1-1:2004 (without confinement, with strain limitation)

This Figure clearly shows that the procedure of the EN1992-1-1:2004 overestimates the failure load for high-strength concrete columns and leads to a non-uniform level of safety. This result is a consequence of the non-consideration of the brittle response of high-strength concrete. In addition, the failure load estimates are overlyconservatives for columns with low to normal concrete strengths.

\section{Influence of confinement due to stirrups}

Although it can be interpreted according to EN1992-1-1:2004 if the confinement conditions shall be accounted for in the calculation of columns, this will be performed in this section in agreement to the general guidelines provided in section \$3.1.9. This phenomenon results in the modification of the effective stress-strain relationship, 
leading to an increase in strength and ductility. Such favourable action is due to the stirrups, that restrain the lateral deformation of concrete in compression, creating a triaxial stress state at the core of the elements. The confined concrete strength is defined as follows in EN1992-1-1:2004:

$$
\begin{array}{lll}
f_{c, c}=f_{c} \cdot\left(1.000+5.00 \sigma_{2} / f_{c}\right) & \text { for } \sigma_{2} \leq 0.05 f_{c} \\
f_{c, c}=f_{c} \cdot\left(1.125+2.50 \sigma_{2} / f_{c}\right) & \text { for } & \sigma_{2}>0.05 f_{c}
\end{array}
$$

where $f_{c, c}$ is the confined compressive strength of concrete and $\sigma_{2}$ is the effective lateral compressive stress due to confinement. The latter is determined by the equilibrium of the stirrups forces and the confining pressure acting in the core of the columns. Considering the effect of confinement, the axial load capacity of concrete columns becomes:

$$
\begin{aligned}
& N_{R}=\sigma_{s} \cdot A_{s}+f_{c} \cdot A_{c}+5 \cdot \sigma_{2} \cdot A_{c s} \quad \text { for } \quad \sigma_{2} \leq 0.05 \cdot f_{c} \\
& N_{R}=\sigma_{s} \cdot A_{s}+1.125 \cdot f_{c} \cdot A_{c}+2.5 \cdot \sigma_{2} \cdot A_{c s} \text { for } \sigma_{2}>0.05 \cdot f_{c}
\end{aligned}
$$

where $A_{c s}$ is the concrete confined area and is defined by the centreline of the external spiral or stirrup. It shall be noted that no clear guidance is available on the efficiency of the different stirrup geometry and spacing and a full efficiency will be assumed. The previous equations are adopted in order to assess the axial load capacity of the investigated specimens. The obtained ratios $N_{\text {test }} / N_{\text {model }}$ are represented as a function of $f_{c}$ in Figure 4.

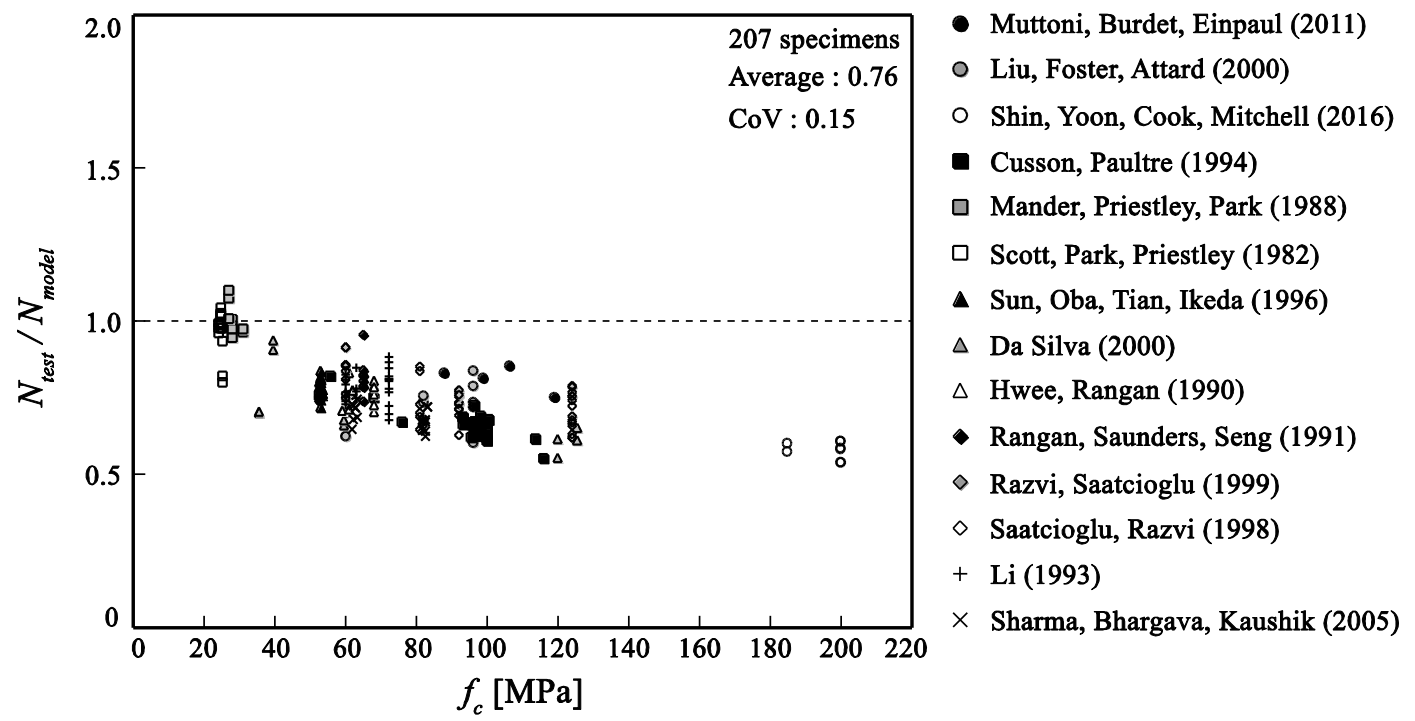

Figure 4. Comparison between column tests and EN1992-1-1:2004 (with confinement, with strain limitation)

It can be noted that the results are even more unsafe compared to the previous calculations without considering the influence of confinement. Again, the safety margin decreases with increasing concrete strength, showing the need for a strength reduction factor accounting for the brittle behaviour of high strength concrete.

\section{Consideration of a brittleness factor $\boldsymbol{\eta}_{\boldsymbol{f}}$}

In this section, the general procedure of the EN 1992-1-1:2004 is modified by considering the brittleness factor $\eta_{f_{c}}$ of MC2010 (Equation 3). The load carrying 
capacity according to the general procedure of the EN 1992-1-1:2004 can thus be expressed as:

$$
N_{R}=\sigma_{s} \cdot A_{s}+\eta_{f c} \cdot f_{c} \cdot A_{c}
$$

The ratio $N_{\text {test }} / N_{\text {model }}$ obtained according to this procedure is represented as a function of the concrete compressive strength $f_{c}$ in Figure 5.

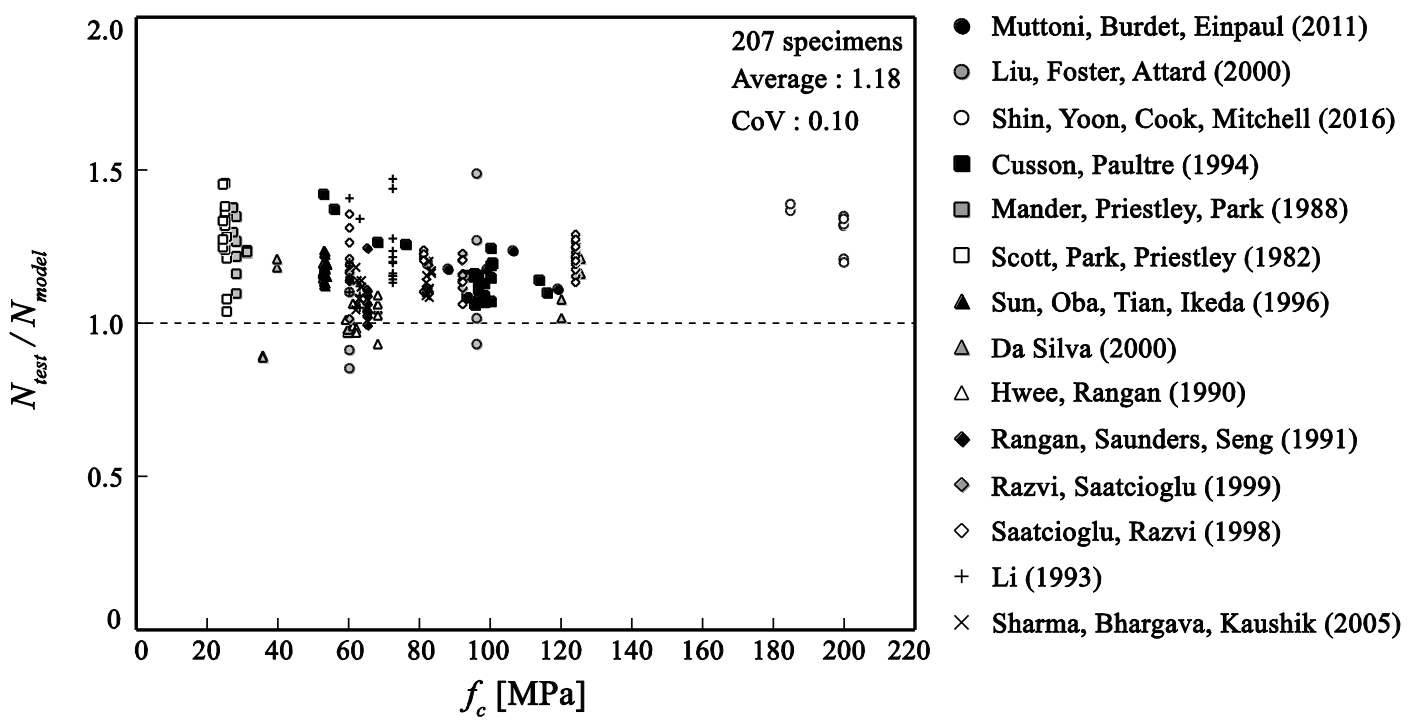

Figure 5. Comparison between column tests and EN1992-1-1:2004 corrected with $\eta_{f c}$ (without confinement, with strain limitation)

Interestingly, by applying the brittleness factor $\eta_{f c}$, the general procedure of the EN 1992-1-1:2004 provides very few unconservative estimates and a rather uniform level of safety. In fact, the failure load predictions appear independent of the concrete strength. The relatively high value on average of the ratio $N_{\text {test }} / N_{\text {model }}$ is to be related to the non-consideration of the favourable effect of confinement due to stirrups. For this reason, the strength reduction factor $\eta_{f c}$ is also applied to the formulation in which the confinement is taken into account. The load carrying capacity is therefore the following:

$$
\begin{array}{ll}
N_{R}=\sigma_{s} \cdot A_{s}+\eta_{f c} \cdot f_{c} \cdot A_{c}+5 \cdot \sigma_{2} \cdot A_{c s} & \text { for } \sigma_{2} \leq 0.05 \cdot f_{c} \\
N_{R}=\sigma_{s} \cdot A_{s}+1.125 \cdot \eta_{f c} \cdot f_{c} \cdot A_{c}+2.5 \cdot \sigma_{2} \cdot A_{c s} & \text { for } \sigma_{2}>0.05 \cdot f_{c}
\end{array}
$$

The evolution of the ratio $N_{\text {test }} / N_{\text {model }}$ as a function of $f_{c}$ is illustrated in Figure 6. In that Figure, the evaluation of the strength of reinforced concrete columns according to EN 1992-1-1:2004 becomes more accurate when both the brittleness factor and the confinement due to stirrups are considered. It is therefore justified to consider the $\eta_{f c}$ factor in order to avoid an overestimation of the failure load of high-strength concrete columns.

\section{RIGID-PLASTIC APPROACH}

In the same manner as for the EN 1992-1-1:2004, the load carrying capacity of concrete columns according to the rigid-plastic approach can be obtained as the sum of the contributions of steel and concrete in compression:

$$
N_{R}=f_{y} \cdot A_{s}+f_{c} \cdot A_{c}
$$




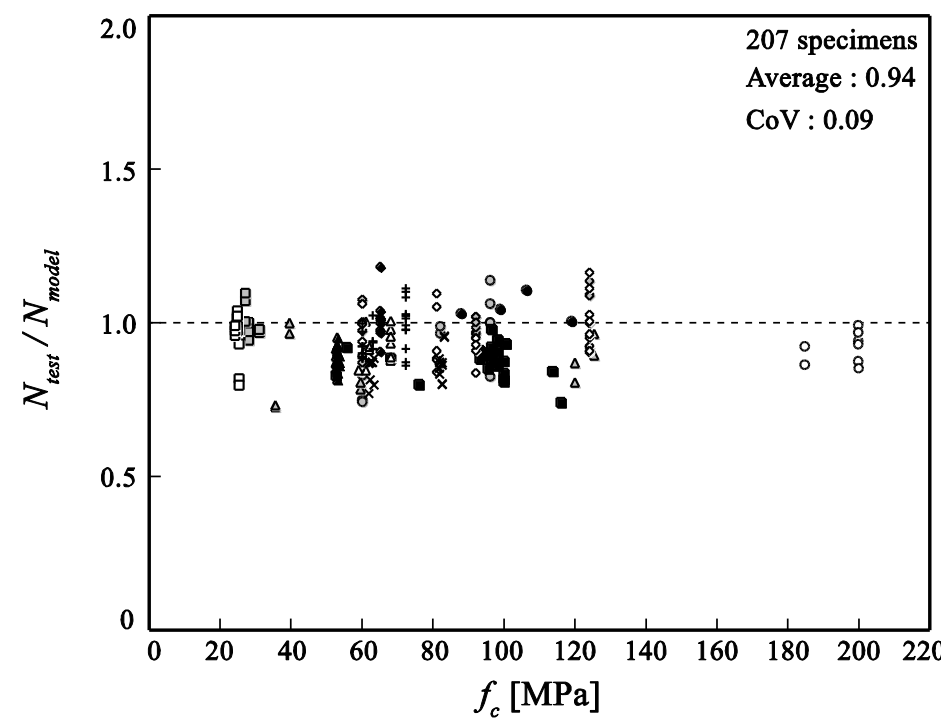

- Muttoni, Burdet, Einpaul (2011)

- Liu, Foster, Attard (2000)

○ Shin, Yoon, Cook, Mitchell (2016)

- Cusson, Paultre (1994)

口 Mander, Priestley, Park (1988)

口 Scott, Park, Priestley (1982)

\ Sun, Oba, Tian, Ikeda (1996)

$\triangle$ Da Silva (2000)

$\triangle$ Hwee, Rangan (1990)

- Rangan, Saunders, Seng (1991)

$\diamond$ Razvi, Saatcioglu (1999)

$\diamond$ Saatcioglu, Razvi (1998)

$+\operatorname{Li}(1993)$

$\times$ Sharma, Bhargava, Kaushik (2005)

Figure 6. Comparison between column tests and EN1992-1-1:2004 corrected with $\eta_{f c}$ (without confinement, with strain limitation)

According to a Mohr-Coulomb assumption for the yield surface of concrete (friction angle of $37^{\circ}$ ), the corresponding strength enhancement due to lateral confinement is the following:

$$
f_{c 3}=f_{c}+4 \cdot\left|\sigma_{2}\right|
$$

where $f_{c 3}$ is the confined concrete strength and the confining pressure $\sigma_{2}$ can be calculated in the same manner as presented in the fib Model Code 2010 §7.2.3.1.6. Considering the brittleness factor $\eta_{f c}$ defined in Equation (3) and the favourable action of confinement, the compressive capacity of a column subjected to pure compression becomes:

$$
N_{R}=f_{y} \cdot A_{s}+\eta_{f c} \cdot f_{c} \cdot A_{c}+4 \cdot\left|\sigma_{2}\right| \cdot A_{c s}
$$

The evolution of the ratio $N_{\text {test }} / N_{\text {model }}$ as a function of $f_{c}$ is depicted in Figure 7.

Following Figure 7, the rigid-plastic approach provides the most accurate prediction of the axial failure load of the investigated specimens, showing little variation in the strength estimates. In addition, it can be noted that thanks to the consideration of the brittleness factor $\eta_{f c}$, the level of accuracy is independent of the concrete compressive strength $f_{c}$.

\section{CONCLUSIONS}

The present paper investigates the suitability of considering a brittleness factor in the strength calculation of concrete columns subjected to pure compression. The main conclusions are summarized below:

- Approaches not considering the influence of concrete brittleness in compression, as EN 1992-1-1:2004, are potentially unsafe for high strength concrete columns. 
- Considering the brittleness factor $\eta_{f c}$ of MC 2010 allows for an accurate and safe estimate of the carrying capacity of columns, with a uniform level of safety.

- A rigid-plastic approach accounting for concrete brittleness in compression provides, despite its simplicity, a very accurate predictions of the load carrying capacity of a column subjected to pure compression.

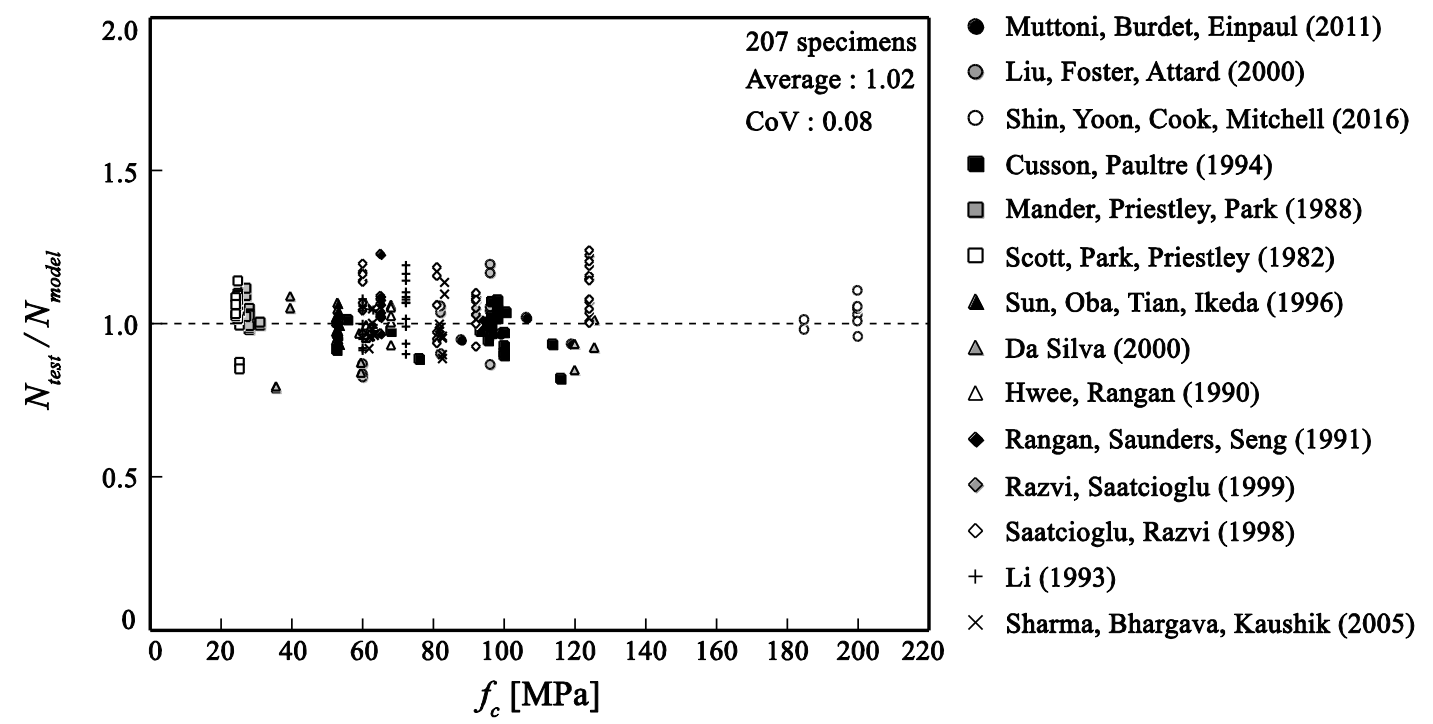

Figure 7. Comparison between column tests and rigid-plastic approach including $\eta_{f c}$ (with confinement, without strain limitation)

\section{REFERENCES}

Cusson D., and Paultre P. (1994). "High-Strength Concrete Columns Confined by

Rectangular Ties." ASCE Journal of Structural Engineering, Vol. 120, No. 3, 783-804.

Da Silva P. (2000). "Effect of Concrete Strength on Axial Load Response of Circular Columns." Master Thesis, McGill University, Montréal, Canada.

EN 1992-1-1:2004 (2004). "Design of Concrete Structures - Part 1: General Rules and Rules for Buildings.” European Committee for Standardization (CEN), Brussels, Belgium.

Exner H. (1979). "On the Effectiveness Factor in Plastic Analysis of Concrete." IABSE reports of the working commissions, Copenhagen.

Fédération Internationale du Béton (2013). "fib Model Code for Concrete Structures 2010.” Ernst \& Sohn, Germany.

Hwee Y. S., and Rangan B. V. (1990). "Studies on Commercial High-Strength Concretes." ACI Materials Journal, V. 87, No. 5, 440-445.

Li B. (1993). "Strength and Ductility of Reinforced Concrete Members and Frames Constructed Using High Strength Concrete." Ph.D Thesis, University of Canterbury, Christchurch, New Zealand.

Liu J., Foster S. J., and Attard M. M. (2000). "Strength of Tied High-Strength Concrete Columns Loaded in Concentric Compression.” ACI Structural Journal, Vol. 97, No. 1, 149-157. 
Mander J. B., Priestley M. J. N., and Park R. (1988). “Observed Stress-Strain Behavior of Confined Concrete.” ASCE Journal of Structural Engineering, Vol. 114, No.8, 1827-1849.

Muttoni A., Burdet O., and Einpaul J. (2011). "Ultimate load capacity of prefabricated concrete column elements." Laboratoire de construction en béton, Mandate SACAC prefabricated columns 11.21.

Muttoni A. (1990). "The Applicability of the Theory of Plasticity in the Design of Reinforced Concrete." (in German: Die Anwendbarkeit der Plastizitätstheorie in der Bemessung von Stahlbeton), Report No. 176, Zürich, Switzerland.

Rangan B. V., Saunders P., and Seng E. J. (1991). "Design of High-Strength Concrete Columns." SP 128-52, ACI International, 851-862.

Razvi S. R. (1995). "Confinement of Normal and High-Strength Concrete Columns." Ph.D. Thesis, University of Ottawa, Canada.

Razvi S. R., and Saatcioglu M. (1999). "Circular High-Strength Concrete Columns under Concentric Compression.” ACI Structural Journal, V.96, No. 5, 817825 .

Saatcioglu M., and Razvi S. R. (1998). "High-Strength Concrete Columns with Square Sections under Concentric Compression", ASCE Journal of Structural Engineering, Vol. 124, No. 12, 1438-1447.

Scott B. D, Park R., and Priestley M. J. N. (1982). "Stress-Strain Behavior of Concrete Confined by Overlapping Hoops at Low and High Strain Rates." ACI Journal, 13-27.

Sharma U. K., Bhargava P., and Kaushik S. K. (2005). "Behavior of Confined High Strength Concrete Columns under Axial Compression.” Journal of Advanced Concrete Technology, Vol. 3, No. 2, 267-281.

Shin H. O., Yoon Y. S., Cook W. D., and Mitchell D. (2016). “Axial Load Response of Ultra-High-Strength Concrete Columns and High-Strength Reinforcement." ACI Structural Journal, V. 113, No. 2, 325-336.

Sun Y. P., Oba T., Tian F. S., and Ikeda T. (1996). "Confinement Effects of Transverse Hoops in High-Strength Concrete." Eleventh World Conference on Earthquake Engineering, Paper No. 1363. 